R Bhandari

P Rayamajhi

DK Baskota

R Pradhan

Ganesh Man Singh Memorial

Academy of ENT and Head and Neck

Studies, TU Teaching Hospital,

Kathmandu, Nepal.

\section{Correspondence to}

Dr. Ramesh Bhandari,

Ganesh Man Singh Memorial

Academy of ENT and Head and Neck

Studies, TU Teaching Hospital,

Kathmandu, Nepal.

Email: doc_bhandari@yahoo.com

Introduction:

\title{
Voice Rehabilitation after Total Laryngectomy in TUTH
}

Esophgeal voice is one of the convenient methods of voice rehabilitation after total Laryngectomy. It is cost effective, hands-free and natural sounding as compared with electrolarynx.

Aims \& objectives:

The objectives of this study were to assess the success rate and to evaluate the quality of esophageal voice in patients with total laryngectomy in Tribhuvan University Teaching Hospital (TUTH).

Materials \& Methods:

A retrospective study was conducted in patients who underwent total laryngectomy for carcinoma of larynx in TUTH between April 2005 to October 2008. Most of them received post operative external beam radiotherapy \& joined training programme for esophageal voice conducted by Laryngectomy Club. Ability of patients to produce speech \& quality of voice were assessed.

Results:

Total Laryngectomy was done in 54 patients for carcinoma of larynx in TUTH in the duration of April 2005 to October 2008. Majority were males (47), youngest age of 38 year \& oldest 85 year. Total Laryngectomy only was done in majority of patients (44) \& additional neck dissection in others. 36 cases joined the esophageal voice training \& all acquired satisfactory speech in the duration of weeks to months.

Conclusion:

Esophageal voice is simple \& safe though time consuming. Post Laryngectomy morbidity has been reduced by it. It has been most common method of voice rehabilitation in our parts due to lack of other methods of rehabilitation.

Key words: Esophageal voice, Total Laryngectomy, Rehabilitation

\section{NTRODUCTION:}

Total Laryngectomy is the surgical procedure in which larynx along with some segment of pharynx is removed resulting in alteration of respiration and voice mechanism. It is mostly done for malignancy of larynx and hypopharynx . Laryngectomee succumb to fear, depression, helpless, disgust due to loss of voice. After the operation, the patient faces the demand of active rehabilitation against a social gradient .There are various options to acquire the new voice by a laryngectomee but esophageal voice is the convenient one due to autonomous production. ${ }^{1}$ It is one of the oldest methods of acquisition of voice after laryngectomy, which is produced by compressing air in to the esophagus and then releasing the air, causing the pharyngo-esophageal segment to vibrate for speech. Tracheoesophageal prosthesis (TEP) and electro larynx are the newer alternative and are popular also. These newer modalities are costly, difficult to maintain and not always applicable .2, 3, ${ }^{4}$ Esophageal voice is hands-free, more natural than electro larynx. Success rate of acquisition of speech varies between 40 \%to $100 \%$. Some of the most significant aspects needing study in the acquisition of speech after laryngectomy are the variables like personality, motivation, and aspiration on levels of the individual subject. These are of more value than physiological and morphological variables. ${ }^{5}$ However esophageal voice training is time consuming and results not always rewarding for usual conversation. ${ }^{6}$ It takes training sessions of weeks to months and drop out rate is equally high. So it is complex and rehabilitationintensive procedure. ${ }^{7}$ But esophageal voice rehabilitation is more important in our part of world where other methods are not commonly used. Our aim of the study is to assess the results of acquisition of esophageal voice and to evaluate the quality of it.

MATERIALS AND METHODS.

This is the retrospective study conducted in Ganesh Man Singh Memorial Academy of ENT-Head and Neck Studies, Institute of
Medicine Kathmandu, Nepal. Study sample was taken from the total laryngectomy performed in the department from April 2005 to October 2008. Preoperative counseling for restoration of voice was done within a week before surgery by the member of laryngectomy club. The latter was established by the group of Laryngectomee who actively participate to teach the new laryngectomee aimed to restore the voice. It is the only center in Nepal for such purpose located in Ganesh Man Singh building, ENT center. Total Laryngectomy and or neck dissection was carried out as per the indication. Post operative radiotherapy (RT) was advised according to the need. Patients were enrolled in the training session of voice restoration of 2-3 hour per day,45 times in a week lasting for weeks to month, conducted by experienced laryngectomee. It was started with vowels, then consonant of Nepalese language. Training continued till satisfactory outcome occurred in the perspective of the patient. Various variables supposed to affect the satisfactory outcome were taken in to consideration. Quality of voice was graded on the basis of adaptation of Wepman's Rating Scale (table1). SPSS software was used for analysis.

Table 1: Adaptation of Wepman's rating scale Level Esophageal sound production Speechproficieny

\begin{tabular}{l|l|l}
\hline 7 & None & $\begin{array}{l}\text { No speech } \\
\text { No speech }\end{array}$ \\
\hline 6 & Involuntary only & No speech \\
\hline 5 & Voluntary part of the time & $\begin{array}{l}\text { Vowel sounds } \\
\text { differentiated; } \\
\text { monosyllabic speech }\end{array}$ \\
\hline 3 & Voluntary most of the time & Single word speech \\
\hline 2 & At will with continuity & Word grouping speech \\
\hline 1 & Automatic & Esophageal speech \\
\hline
\end{tabular}
RESULTS

Total Laryngectomy was done in 54 patient and 36 (66.7\%) were enrolled in the session. Minimum age was 38 years and maximum 
age was 85 years with mean age 59.6 year. There were $32(89 \%)$ males and $4(11 \%)$ females. Most common age group was $61-70$ year (16), followed by 51-60 years (8), 41-50 years (8).

Fig 1: Age distribution
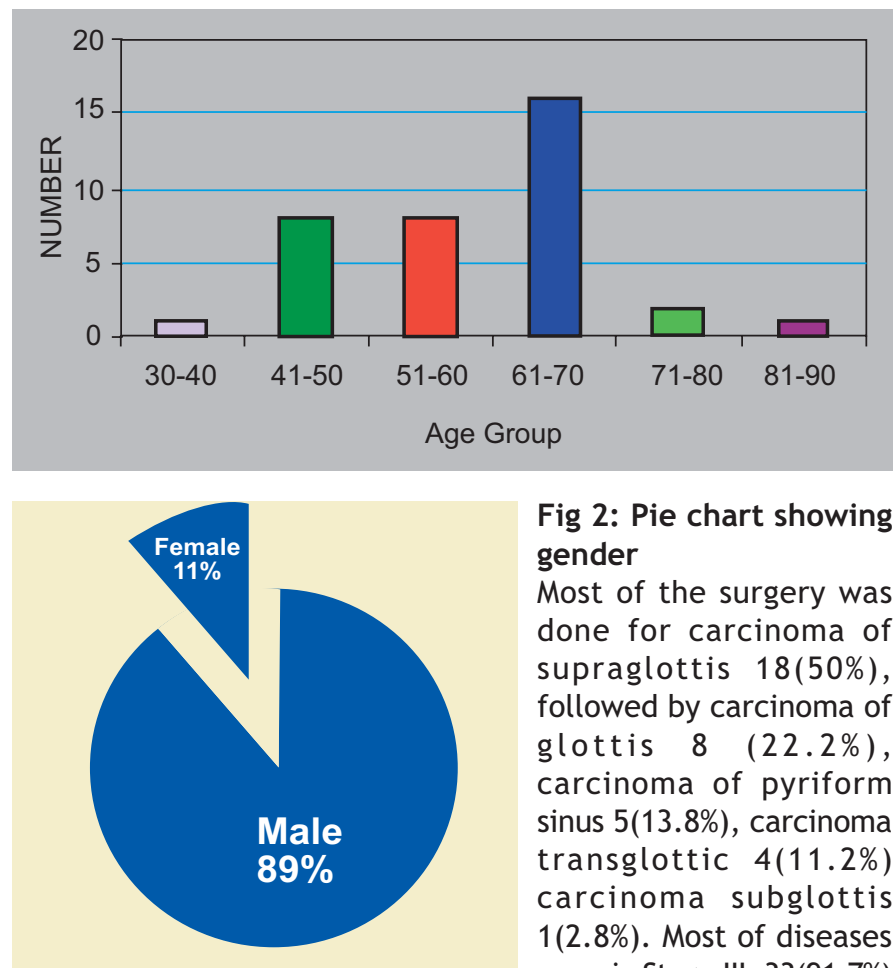

Fig 2: Pie chart showing gender

Most of the surgery was done for carcinoma of supraglottis $18(50 \%)$, followed by carcinoma of glottis $8(22.2 \%)$, carcinoma of pyriform sinus $5(13.8 \%)$, carcinoma transglottic $4(11.2 \%)$ carcinoma subglottis $1(2.8 \%)$. Most of diseases were in Stage III: 33(91.7\%)

then Stage IV: 3(8.3\%)

Fig 3: Sites of involvement by malignant lesion

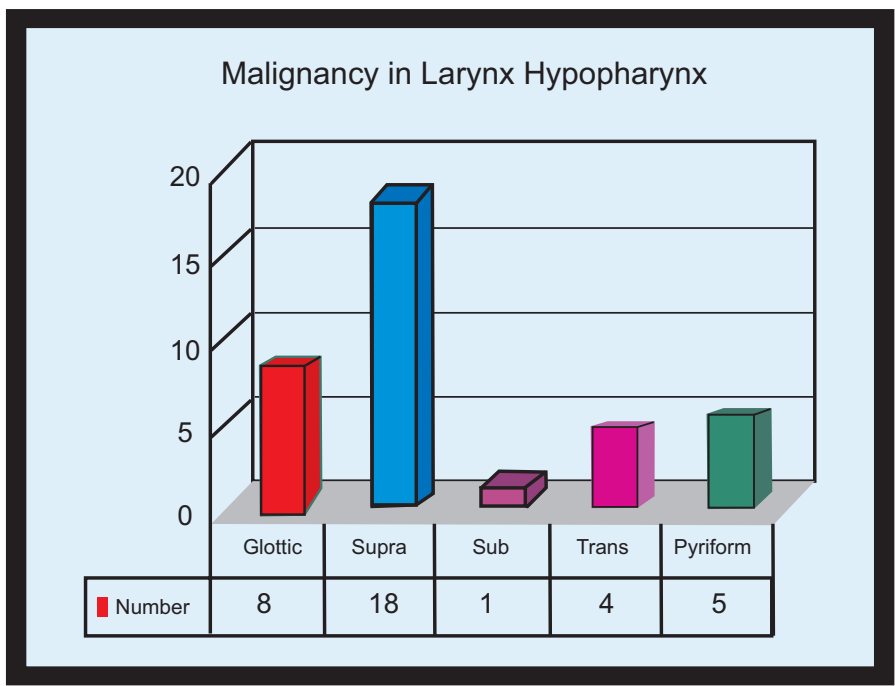

Total Laryngectomy was done in 32(88.9\%) and Total Laryngectomy with radical neck dissection( RND) was done in $4(11.1 \%)$ cases. 32( $88.9 \%$ ) patients received post operative radiotherapy before joining the training session. Minimum and maximum time to attend the session after surgery was 2 and 14 months respectively with mean 5.7 months. The time duration required to achieve the understandable speech was between 2 and 3 month with average 2.3 months (table2).

Table 2

\begin{tabular}{l|l|l|l} 
& $\begin{array}{l}\text { Minimum } \\
\text { (month) }\end{array}$ & $\begin{array}{l}\text { Maximum } \\
\text { (month) }\end{array}$ & $\begin{array}{l}\text { Mean } \\
\text { (month) }\end{array}$ \\
$\begin{array}{l}\text { Gap between surgery } \\
\text { \& speech joining } \\
\text { training }\end{array}$ & 2 & 14 & 5.7 \\
$\begin{array}{l}\text { Duration to acquire } \\
\text { speech }\end{array}$ & 2 & 3 & 2.3
\end{tabular}

All Laryngectomee who had taken the session acquired some sort of speech and level 2 outnumber by $63.9 \%$, followed by level 3. Most of the cases had not received the formal education. Mean age of level 2 cases was $61.7 \%$ (table 3 ).

Table 3:

\begin{tabular}{|c|c|c|c|c|}
\hline Quality & $\begin{array}{l}\text { Number } \\
(n=36)\end{array}$ & Gender & $\begin{array}{l}\text { Mean age } \\
(\mathrm{yr})\end{array}$ & Education \\
\hline Level 3 & $8(22.3 \%)$ & $M=6 F=2$ & 56 & $\begin{array}{l}\text { Not Formal } \\
\text { Education } \\
(\mathrm{NFE})=6(75 \%) \\
\text { Educated: } 2(25 \%)\end{array}$ \\
\hline Level 2 & $23(63.9 \%)$ & $M=21 F=2$ & 61.7 & $\begin{array}{r}\text { NFE }=18(78.2 \%) \\
\text { Educated }=5(21.8 \%)\end{array}$ \\
\hline Level 1 & $5(13.8 \%)$ & $M=5$ & 55.8 & $\begin{array}{l}\text { NFE }=3(60 \%) \\
\text { Educated }=2(40 \%)\end{array}$ \\
\hline
\end{tabular}

None of the laryngectomee had psychiatry disease in pre and post operative period.

DISCUSSION:

Esophageal voice is the most common method of voice rehabilitation in our part but enrollment is only $66.7 \%$. This may be due to lack of awareness, helplessness, and lack of services outside the valley. No previous reports from the same centre are available but this is high rate as compared to other center's study where other new modalities are popular. Speech proficiency, even single word speech that is sufficient to communicate is defined success here. So success rate is $100 \%$ which may be due to only available option here. A result of esophageal speech from other centre is 8.5- $41.5 \%{ }^{8}$ Minako et $\mathrm{al}^{9}$ showed $27(41.5 \%)$ acquired practical esophageal speech and 59(90.8\%) acquired either esophageal or electrolarynx speech. Six (9.2\%) could not acquire any laryngeal speech. Drop rate from session is also very high in other study because of long time required for acquisition and other methods are also available. Average duration to attend the rehabilitation is $\mathbf{5 . 7}$ months which is late. Lack of interest, financial constrains might play the role. Most of the larygectomee (63.9\%) acquired level 2 speech. Shames et al2 reported age, removal of strap muscle, pre-surgical knowledge of resulting voice problem, number of speech session are the significant variables. Age, educational \& psychologic variable are not important. ${ }^{3}$ Most of the patients (75\%) had not received the formal education in our study. Voice rehabilitation in the past has primarily been with the electrolarynx or esophageal speech. Tracheoesophageal puncture (TEP) is a technique that has replaced the other two methods as the rehabilitative procedure of choice in most total laryngectomy patients. ${ }^{6}$ It is of primary and secondary type depending upon 
the puncture made during laryngectomy or after surgery respectively. Manual dexterity, costly for the maintainance, chances of fungal growth are the drawbacks of this kind of rehabilitation. Electrolarynx is also costly and poor quality of speech. Age has no association with outcome of rehabilitation. Educated laryngectomee seems to have an inferior outcome which is due to less number of subjects.

\section{CONCLUSION}

Esophageal voice is the safe, cost effective, convenient method of voice rehabilitation after Total Laryngectomy. Though time consuming, success rate is $100 \%$. Most laryngectomee acquired satisfactory speech (Level 2). Retrospective and small sample size is the limitation of this study. Prospective with larger sample size, multicentric study is recommended.

\section{REFERENCES}

1. Wepmang M, Macgahan A, Rickard JC and Sheltonn W. The objective measurement of progressive esophageal speech development. Speech Hearing Dis(1953); 18:247-251.

2. Shames GH, Font J. and Matthews J. Factors related to speech proficiency of the laryngectomized. J. Speech Hearing Dis (1963), 28: 273-287.
3. Keith RL, Ewert C and Flowers R. Factors Influencing the Learning of Esophageal Speech. International Journal of Language \& Communication Disorders 1974,9:2,110-116

4. Motta G. La riabilitazione vocale del laringectomizzato con protesi tracheo-esofagea [in Italian]. Acta Otorhinolaryngol Ital. 1988; 8(suppl 20):157-164.

5. Kesteloot K, Nolis I, Huygh J, Delaere P, Feenstra L. Costs and effects of tracheoesophageal speech compared with esophageal speech in laryngectomy patients. Acta Otorhinolaryngol Belg. 1994;48:387-394.

6. Boyd JH, Varvares M, Fitzmaurice S. Voice rehabilitation after Laryngectomy. Mo Med 1995 Mar;92(3):145-7.

7. Culton GL, Gerwin JM. Current trends in laryngectomy rehabilitation: a survey of speech-language pathologists. Otolaryngol Head Neck Surg. 1998;118:458-463.

8. Hillman RE, Walsh MJ, Wolf GT, Fischer SG, Hong WK for the Research Speech-Language Pathologists, Department of Veterans Affairs Layngeal Cancer Study Group. Functional outcomes following treatment for advanced laryngeal cancer. Ann Otol Rhinol Laryngol Suppl. 1998;172:1-27.

9 Minako K, Noriko K, Hajime H, Yuki H. Speech rehabilitation aftertotal Laryngectomy...Acta oto-laryngologica. Supplementum 2002,547(25): 107-112.

\section{Our Innovation, Quality control and concern are rewarded only with your prescription Marks of}

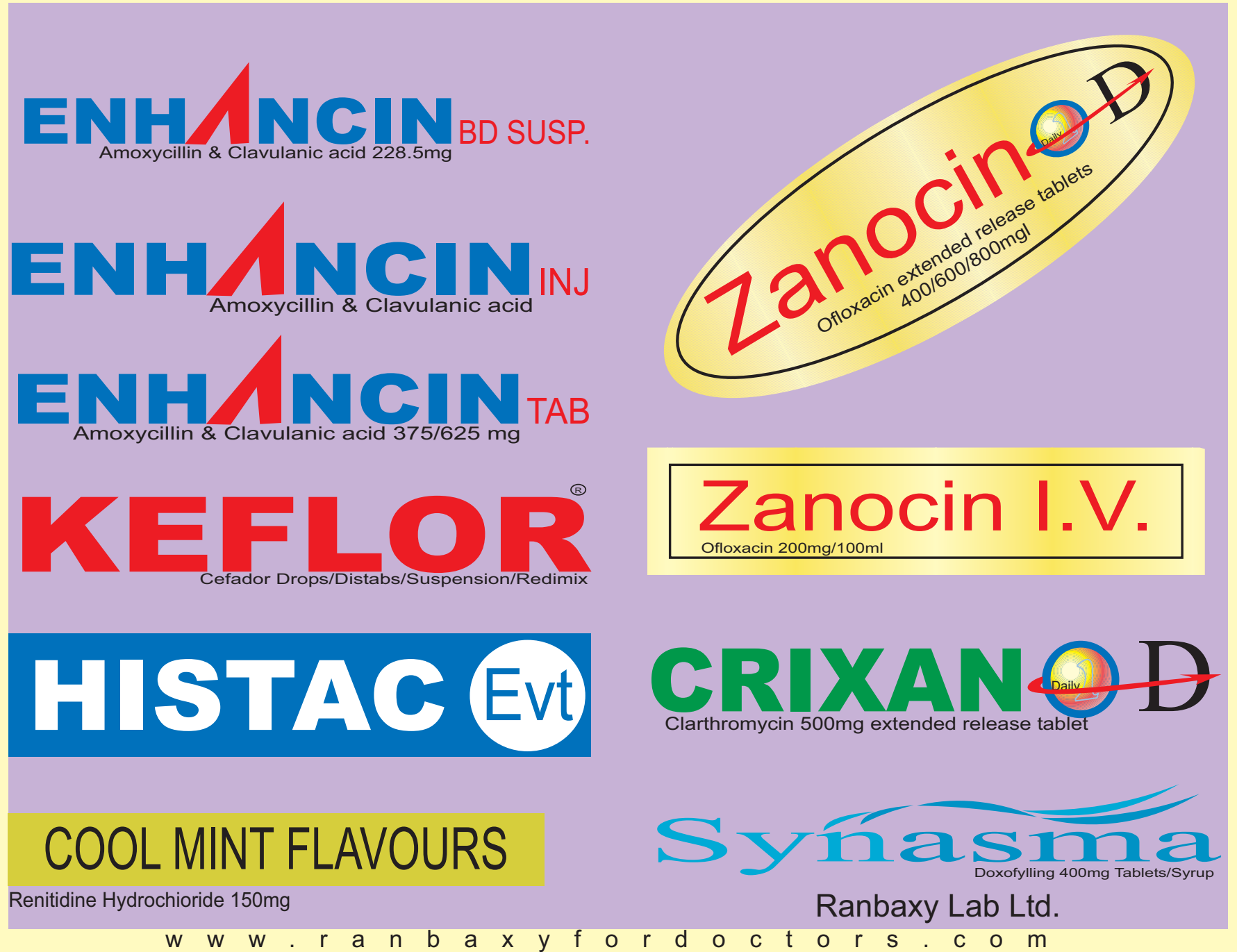

